\title{
Profiling Pretomanid as a Therapeutic Option for TB Infection: Evidence to Date
}

\author{
Stephani L Stancil ${ }^{1-3}$ \\ Fuad Mirzayev ${ }^{4}$ \\ Susan M Abdel-Rahman ${ }^{2,3}$ \\ 'Division of Adolescent Medicine, \\ Children's Mercy Kansas City, Kansas \\ City, MO, 64108, USA; ${ }^{2}$ Division of \\ Clinical Pharmacology, Toxicology and \\ Therapeutic Innovation, Children's Mercy \\ Kansas City, Kansas City, MO, 64I08, \\ USA; ${ }^{3}$ Department of Pediatrics, \\ University of Missouri-Kansas City \\ School of Medicine, Kansas City, MO, \\ 64108, USA; ${ }^{4}$ World Health \\ Organization, Geneva, Switzerland
}

\begin{abstract}
Tuberculosis (TB) is the most deadly infectious disease globally. Although most individuals achieve a cure, a substantial portion develop multi-drug resistant TB which is exceedingly difficult to treat, and the number of effective agents is dwindling. Development of new anti-tubercular medications is imperative to combat existing drug resistance and accelerate global eradication of TB. Pretomanid (PA-824) represents one of the newest drug classes (ie, nitroimidazooxazines) approved in 2019 by the United States Food and Drug Administration as part of a multi-drug regimen (with bedaquiline and linezolid, BPaL) and recommended by the World Health Organization (WHO) to treat extensively-resistant (XRTB) and multi-drug resistant tuberculosis (MDR-TB). Approval was granted through the FDA's Limited Population Pathway for Antibacterial and Antifungal Drugs, which accelerates approval for antimicrobial drugs used to treat life-threatening or serious infections in a limited population with unmet need. This review details the pharmacology, efficacy, and safety of this new agent and describes evidence to date for its role in the treatment of drug resistant TB including published, ongoing, and planned studies.
\end{abstract}

Keywords: pretomanid, tuberculosis, antimicrobial, multi-drug resistant

\section{Background}

Tuberculosis (TB) is estimated to infect $25 \%$ of the world's population and is the most deadly infectious disease globally. ${ }^{1}$ Nearly $85 \%$ of individuals with TB achieve a cure; however, a substantial portion of individuals develop drugresistant TB which has become increasingly difficult to treat, largely due to variant strains exhibiting resistance to multiple medications. ${ }^{1}$ Development of new antitubercular medications is imperative to combat existing drug-resistance and accelerate global eradication of TB.

Pretomanid (PA-824) represents one of the newest drug classes (ie, nitroimidazooxazines) approved for the treatment of TB. Pretomanid was approved by the United States Food and Drug Administration (FDA) in August 2019 as part of a multi-drug regimen (with bedaquiline and linezolid, $\mathrm{BPaL}$ ) to treat extensivelyresistant (XR-TB) and multi-drug resistant tuberculosis (MDR-TB). Approval was granted through the FDA's Limited Population Pathway for Antibacterial and Antifungal Drugs, which accelerates approval for antimicrobial drugs used to treat life-threatening or serious infections in a limited population with unmet need. Since that time, pretomanid has also been approved for limited use in India and granted marketing authorization by the European Medicines Agency (EMA). This review will detail the pharmacology of this new agent and describe evidence to
Correspondence: Susan M Abdel-Rahman Division of Clinical Pharmacology, Toxicology and Therapeutic Innovation, Children's Mercy Kansas City, 240 Gillham Road, Kansas City, MO, 64I08, USA

Tel +| 8|6-73|-7|64

Email srahman@cmh.edu 


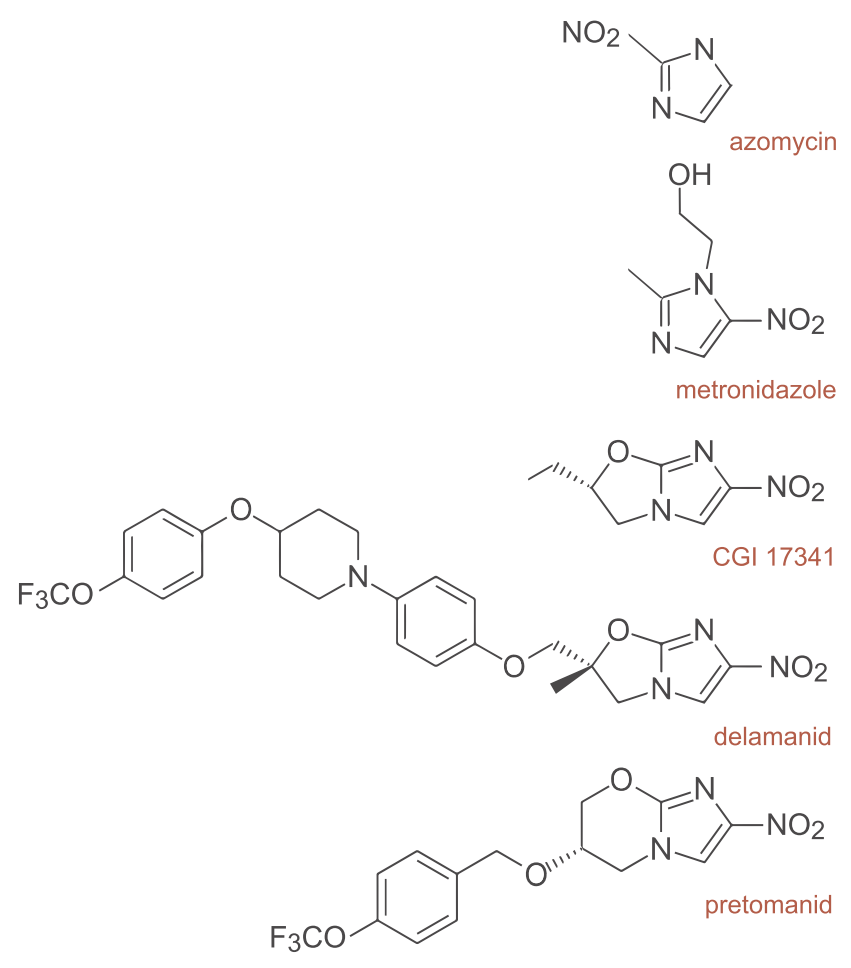

Figure I Structural relationships between the nitroimidazoles, nitroimidazooxazoles, and nitroimidazopyrans.

date for its role in the treatment of drug resistant TB including published, ongoing, and planned studies.

\section{Chemical Properties}

Pretomanid represents the class of nitroimidazopyrans (NAP) which are derivatives of nitroimidazoles such as azomycin and metronidazole (Figure 1). The more immediate precursor of pretomanid is Ciba-Geigy compound CGI-17341 which was originally investigated as a radiosensitizer for chemotherapy and discovered to be mutagenic. It also demonstrated antimycobacterial activity which prompted the synthesis of several hundred bicyclic nitroimidazooxazoles (eg, delamanid) and NAPs including pretomanid that did not demonstrate mutagenicity. Readers interested in details about NAP stereochemistry are referred to the following references. ${ }^{2-6}$

\section{Mechanism of Action Non-Replicating Bacteria}

Under anaerobic conditions, the putative mechanism of action for nitroimidazole prodrugs involves reductive "activation" within the mycobacteria to reactive nitro radical anion intermediates that are capable of interacting with cellular components and interrupting cellular respiration
(Figure $2 \mathrm{~A}) .^{7}$ In MTb, NAP reduction is mediated by the bacterial deazaflavin-dependent nitroreductase (Ddn). ${ }^{8}$ Ddn relies on the reduced form of cofactor $F_{420}$ (ie $\mathrm{F}_{420} \mathrm{H}_{2}$ ), as an electron donor. $\mathrm{F}_{420} \mathrm{H}_{2}$ is generated during the oxidation of glucose-6-phosphate to 6-phosphogluconate which is mediated by $\mathrm{F}_{420}$-dependent glucose-6-phosphate dehydrogenase (Fgd). Contributing to the biosynthesis of $\mathrm{F}_{420}$ are the proteins fbiA, fbiB, fbiC, and fbiD (Figure 2A).

Subsequent protonation of pretomanid can also generate desnitro metabolites and nitrous acid which further decompose to nitric oxide. One investigation demonstrated that cellular nitric oxide production increases in a dosedependent manner following anaerobic co-incubation of M. bovis cultures with pretomanid. ${ }^{8}$ It should be noted that only the lowest pretomanid concentrations evaluated in this study reflect those that can reasonably be expected in the plasma at steady-state following administration of the approved $200 \mathrm{mg}$ once daily dose. Consequently, the contribution of nitric oxide release to efficacy in mycobacterial lesions and infected immune cells remains to be confirmed. However, preclinical rat disposition data do suggest that autoradiographic signals in lung 4 hours after oral administration of $\left[{ }^{14} \mathrm{C}\right]$ pretomanid are approximately $50 \%$ higher than observed in blood. ${ }^{9}$

\section{Replicating Bacteria}

Pretomanid demonstrates the ability to inhibit protein and lipid biosynthesis under conditions where nucleic acid synthesis remains unaffected. ${ }^{2}$ One proposed mechanism suggests that pretomanid reduces the availability of keto mycolic acids, components of the cell wall lipid bilayer, by impairing oxidative transformation of precursor hydroxymycolates (Figure 2B). ${ }^{2,10}$ Whether this reflects direct action on the deazaflavin cofactor $\mathrm{F}_{420}$-dependent hydroxymycolic acid dehydrogenase (fHMAD) ${ }^{11}$ or indirect action upstream of this enzyme is unclear from these reports.

A more recent study examining MTb metabolomic signatures mid-log phase suggests that pretomanid targets the pentose phosphate pathway resulting in the accumulation of phosphate sugars. ${ }^{12}$ This leads to the toxic accumulation of methylglyoxal, a highly reactive ketoaldehyde that glycates nucleic acids and proteins prompting cellular arrest. $^{12,13}$ Given the redox relationship between Ddn and Fgd illustrated in Figure 2A, this proposed mechanism may impact latent bacteria as well as replicating bacteria. Notably, this study confirms a mechanism of action wholly 


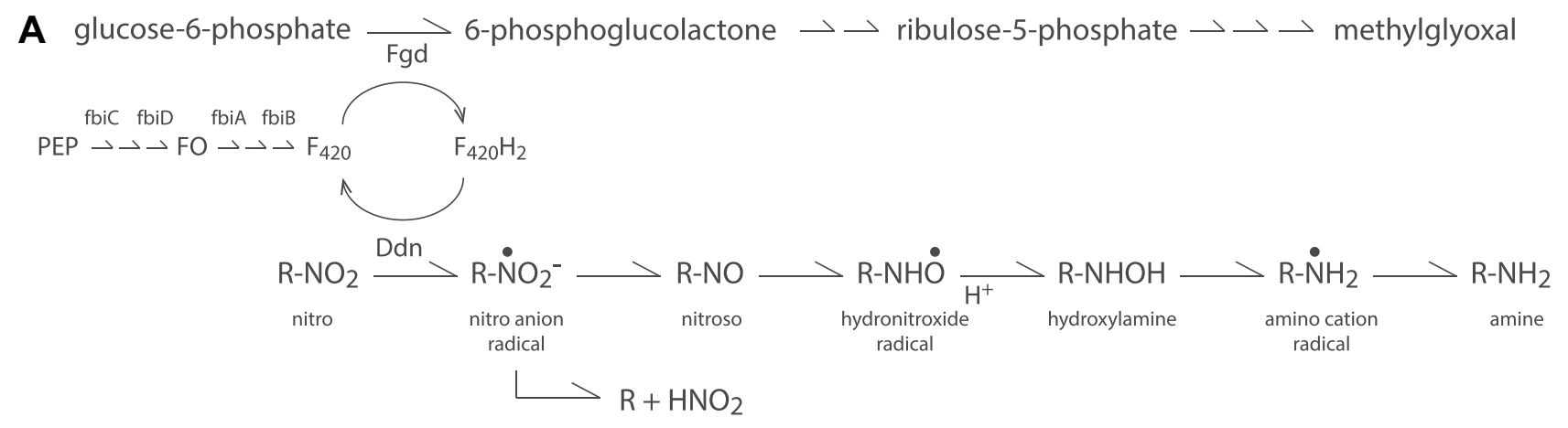

B

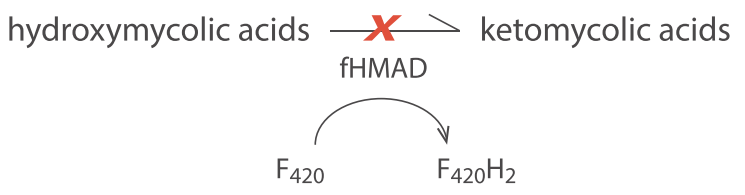

Figure 2 (A) Intracellular activation pathway for nitroimidazoles. (B) Keto mycolic acid synthesis pathway. Pretomanid blocks formation of keto mycolic acids, a component of the cell wall, by impairing oxidation of precursor, hydroxymycolic acid.

distinct from other agents used to treat MTb including ampicillin, ethambutol, ethionamide, isoniazid, kanamycin, linezolid, rifampin, and streptomycin. ${ }^{12}$

\section{Mechanisms of Resistance}

Nitroimidazopyran-resistant mutants do not efficiently reduce nitroaromatic compounds and do not appear to generate the polar reactive metabolites of pretomanid. ${ }^{2}$ For mutants selected in vitro, this inability to activate pretomanid has been linked to sequence variations in the same genes responsible for its activity, namely those encoding Ddn, Fgd, and the proteins involved in $\mathrm{F}_{420}$ biosynthesis (fbiA, fbiB, fbiC) (Figure 2A). ${ }^{14-17}$ Resistance explained by sequence variations in these 5 genes accounted for $83 \%$ of the isolates examined in one study (Ddn 29\%, Fgd 7\%, fbiA 19\%, fbiB 2\%, fbiC 26\%). The remaining $17 \%$ of isolates demonstrated no identifiable sequence variations in these genes, suggesting the presence of additional loci that mediate resistance. ${ }^{14}$

A more recent study may elucidate the missing mechanism(s). An investigation of spontaneous mutants isolated in vivo from a murine model attributed pretomanid resistance in $90 \%$ of isolates to the same 5 genes noted previously, with a similar rank order (Ddn 12\%, Fgd 4\%, fbiA $15 \%$, fbiB $4 \%$, fbiC $55 \%$ ). In the remaining $10 \%$ of isolates, the authors were able to attribute resistance to sequence variations in what they identified as CofC (RV2983). Wild-type Rv2983 paired with a variant
RV2983 restored pretomanid susceptibility. Notably, CofC appears to be the archaeal homolog of bacterial $\mathrm{fbiD}^{18}$ and thus may also be involved in $\mathrm{F}_{420}$ biosynthesis. ${ }^{19}$

Though genes involved with the $\mathrm{F}_{420}$-dependent pathway play a role in managing oxidative stress, with limited exception, they are not represented among those that appear to be required for the growth and survival of $\mathrm{MTb}{ }^{20-24}$ Functional or structural analogs of these proteins contribute to redundancy in this organism rendering little loss in mycobacterial fitness despite disruption of the genes. Accordingly, mutations easily arise under selection pressure explaining the diversity of sequence variations that have been observed in resistant mutants. ${ }^{14,19,25}$ The exceptions are fbiC, where knockout mutants are found to be hypersusceptible to oxidative stress generated by selected naphthoquinones, ${ }^{26}$ and Ddn mutants where inactivation seems to affect the resuscitation of dormant bacilli. $^{25}$

Recent data also illustrate the importance of monitoring resistance to other agents in the approved regimen. The $r p l C$ gene encodes ribosomal protein L3 which is involved with antimicrobial binding, ${ }^{27}$ and $r p l C$ variants have been reported to confer resistance to oxazolidinone (eg, linezolid). ${ }^{28}$ In a recent study of induced dual resistant (Iinezolid and pretomanid) MTB strains, variants in the $r p l C$ gene occurred with high frequency ( $\geq 86 \%$ ) and were more virulent in mice. ${ }^{27}$ Monitoring for the emergence of 
resistance with clinical use of the $\mathrm{BPaL}$ regimen will be essential.

\section{Emergence of Resistance}

Several studies have examined the frequency of spontaneous resistance to pretomanid in vitro (TB Alliance, personal communication data). ${ }^{2,14,29}$ The data suggest a mutation frequency $\left(10^{-5}\right.$ to $\left.10^{-7}\right)$ greater than that of rifampin but comparable to other agents including isoniazid, ethambutol, and pyrazinamide. ${ }^{30}$ Spontaneous mutation rates appear to be influenced by the concentration of pretomanid to which the isolates are exposed and the starting mycobacterial inoculum. Considering putative mycobacterial loads at time of diagnosis and consistent with the traditional approach to MTb treatment, pretomanid should be used in combination with other antimycobacterial agents.

The emergence of pretomanid resistance in treatment has also been described in animal models, ${ }^{31,32}$ but data on frequencies are limited. In BALB/c and $\mathrm{C} 3 \mathrm{HeB} / \mathrm{FeJ}$ mice infected with $\mathrm{MTb} \mathrm{H} 37 \mathrm{Rv}$ via aerosol, investigators observed a dose-dependent increase in spontaneous pretomanid-resistance. ${ }^{19}$ The spontaneous frequency of resistant mutants could not be estimated in untreated $\mathrm{C} 3 \mathrm{HeB} /$ FeJ mice because they succumbed early. However, BALB/ c mice demonstrated spontaneous resistance, in the absence of pretomanid exposure, at a rate of $\sim 10^{-5}$ and the fraction of total CFU constituted by pretomanidresistant isolates increased in direct proportion with dose up to $300 \mathrm{mg} / \mathrm{kg}^{19}$ In a second study of 4- to 6-week-old female BALB/c mice infected with MTb (strain H37Rv, MIC $0.125 \mu \mathrm{g} / \mathrm{mL}$ ), the proportion of CFU resistant to pretomanid monotherapy after 2 months of treatment $(100 \mathrm{mg} / \mathrm{kg})$ was $3.8 \times 10^{-3} \cdot 33$ In combination with $\mathrm{INH}$, the proportion of CFU resistant to pretomanid dropped to $5.0 \times 10^{-6} .33$ These data similarly highlight the potential for selective amplification of pretomanid resistance. However, the sponsor reported no emergence of resistance in the human EBA studies (albeit with methodologic limitations) (TB Alliance, personal communication data).

With respect to cross resistance, the sponsor examined susceptibility profiles for 9 pretomanid resistant MTb H37Rv strains (MGIT MIC > $16 \mu \mathrm{g} / \mathrm{mL}$ ); 6 isolated from the lungs of infected mice that had been treated with pretomanid and 3 spontaneous mutants selected on pretomanid-containing plates. Their study revealed that 8 of the 9 strains were found to be resistant to delamanid and 1 strain each was resistant to kanamycin and pyrazinamide. All 9 isolates remained susceptible to amikacin, bedaquiline, capreomycin, clofazimine, ethambutol, ethionamide, isoniazid, linezolid, moxifloxacin, ofloxacin, rifampin, and streptomycin (TB Alliance, personal communication data). Among $22 \mathrm{MDR}$ and extremely drug resistant (XDR) $\mathrm{MTb}$ isolates originating from the Tuberculosis Biobank at the National Clinical Laboratory on Tuberculosis (Beijing, China), 5 of 7 delamanidresistant isolates ( $\mathrm{MIC} \geq 16$ ) were susceptible to pretomanid (MIC 0.016 to $0.063 \mathrm{mg} / \mathrm{L}$ ). ${ }^{16}$ An additional 2 pretomanid-resistant isolates were susceptible to delamanid. Pretomanid activity was also evaluated in MTb H37Rv isolates, resistant to the more recently discovered nitrofuranylamides (NFAs) and 5-nitrothiophenes (5NP) which share structural features with pretomanid and delamanid. Of 25 NFA-resistant isolates, 8 were cross resistant to pretomanid, 11 were resistant to delamanid, and 7 were resistant to both suggesting incomplete cross resistance between these structurally similar compounds. ${ }^{34}$ All 11 of the 5NP-resistant isolates were fully cross-resistant to pretomanid. $^{35}$

\section{Spectrum of Activity Mycobacterium tuberculosis}

Under routine culture conditions, minimum inhibitory concentrations (MIC) for pretomanid against drug-susceptible (DS), monoresistant, MDR, and XDR isolates of MTb range from $0.005-0.48 \mu \mathrm{g} / \mathrm{mL}$ (TB Alliance, personal communication data). These data suggest that resistance phenotype has limited impact on pretomanid activity. MICs increase approximately 3- to 4-fold in the presence of $4 \%$ human albumin and more than 6 -fold in the presence of $50 \%$ human serum. ${ }^{36,37}$ Minimum bactericidal concentrations (MBC) against MTb H37Rv under aerobic conditions $(0.02 \mu \mathrm{g} / \mathrm{mL})$ are approximately twice that of the MIC $(0.01 \mu \mathrm{g} / \mathrm{mL})$ while non-replicating mycobacteria in low-oxygen conditions demonstrate an $\mathrm{MBC}(6.3 \mu \mathrm{g} /$ $\mathrm{mL})$ approximately 7.5 -fold higher than the $\mathrm{MIC}(0.82 \mu \mathrm{g} /$ $\mathrm{mL}$ ) (TB Alliance, personal communication data).

\section{Non-MTb Species}

Pretomanid demonstrates activity against other species in the Mycobacterium tuberculosis complex (MTBC) including $M$. bovis, M. africanum, and $M$. pinnipedii (MIC range $<0.0312$ to $0.125 \mu \mathrm{g} / \mathrm{mL}$ ). Activity against M. ulcerans $(\leq 4$ to $\geq 16 \mu \mathrm{g} / \mathrm{mL})$ and $M$. canettii $(8 \mu \mathrm{g} / \mathrm{mL})$ is reduced while no activity is seen against $M$. phlei, 
M. smegmatis, M. fortuitum, M. smegmatis, M. leprae and $M$. avium complex (TB Alliance, personal communication data). ${ }^{38}$ Activity against $M$. kansasii may be reduced $(8 \mu \mathrm{g} / \mathrm{mL})$ or non-existent (TB Alliance, personal communication data). ${ }^{38}$ When examined for activity against commonly encountered non-mycobacterial species, pretomanid demonstrated no appreciable activity against Streptococcus pneumoniae, S. pyogenes, S. mutans, Staphylococcus aureus, S. epidermidis, Enterococcus faecalis, E. faecium, Haemophilus influenzae, Moraxella catarrhalis, Escherichia coli and Enterobacter cloacae (MIC >128 $\mu \mathrm{g} / \mathrm{mL}$ ). Activity against Candida albicans was also absent (MIC $>50 \mu \mathrm{g} /$ $\mathrm{mL}$ ) (TB Alliance, personal communication data).

When tested on a panel of anaerobic bacterial species including gram-positive, gram-negative and microaerophilic, pretamonid was largely ineffective with MIC ranging from 2 to $>32 .^{39}$ Pretamonid, and the structurally similar metronidazole, were similarly ineffective against $H$. pylori in this in vitro panel. Given that metronidazole is an effective clinical tool against anaerobic infections, these data should be interpreted with caution. Pretomanid activity (MIC) against the various species were as follows: C. difficile $(2 \mathrm{ug} / \mathrm{mL}), \quad$ L. acidophilus $(>32 \mu \mathrm{g} / \mathrm{mL})$, G. vaginalis $(>32 \mu \mathrm{g} / \mathrm{mL}), \quad P$. micros $(<32 \mu \mathrm{g} / \mathrm{mL})$, P. asaccharolytica $(2 \mu \mathrm{g} / \mathrm{mL}), P$. acnes $(>32 \mu \mathrm{g} / \mathrm{mL}), B$. fragilis $(16 \mu \mathrm{g} / \mathrm{mL})$, B. longum $(>32 \mu \mathrm{g} / \mathrm{mL}), F$. nucleatum $(4 \mu \mathrm{g} / \mathrm{mL})$, M. mulieris $(>32 \mu \mathrm{g} / \mathrm{mL})$, P. bivia $(32 \mu \mathrm{g} / \mathrm{mL})$, V. parvula (>32 $\mu \mathrm{g} / \mathrm{mL})$, H. pylori $(16 \mu \mathrm{g} / \mathrm{mL})$.

\section{Pre-Clinical Activity}

The intracellular activity of pretomanid against MTb (6.42 $\log _{10} \mathrm{CFU}$ ) has been investigated in macrophages differentiated from human THP-1 monocytes. Following 4 hours of drug exposure and an additional 68-hours of culture, viable bacterial counts revealed that the intracellular potency of pretomanid appears comparable to isoniazid (INH) and inferior to delamanid and rifampin by 3-fold and 2-fold, respectively. ${ }^{40}$ Though intracellular: extracellular ratios vary by drug and incubation condition, average extracellular (peak plasma) concentrations $(\mu \mathrm{g} / \mathrm{mL})$ are 0.2-0.6 (delamanid), 5-15 (rifampin), 1.1-2.2 (pretomanid), and 3-10 (isoniazid). ${ }^{41-43}$

In animal models, initial investigations into relative NAP activity against a luminescent strain of MTb $\mathrm{H} 37 \mathrm{Rv}$ illustrated that pretomanid is as active as metronidazole and more active than its predecessor CGI 17341 or isoniazid against static MTb. ${ }^{2}$ Early studies also examined the activity of pretomanid in a BALB/c murine model where the same luminescent strain of MTb H37Rv was injected by tail vein. These data offer evidence of a doseresponse relationship and allude to potency that is comparable to $\mathrm{INH}^{2}{ }^{2}$ Subsequent dose ranging studies (3.125 to $200 \mathrm{mg} / \mathrm{kg}$ ) in a BALB/c murine aerosol model set out to establish the minimum effective dose (MED), defined as the lowest dose capable of preventing the development of gross lesions in the lung and spleen, and the minimum bactericidal dose (MBD), defined as the lowest dose that reduces lung CFU by $99 \%$. In mice these were determined to be $12.5 \mathrm{mg} / \mathrm{kg}$ and $100 \mathrm{mg} / \mathrm{kg}$, respectively. ${ }^{33}$ Independent rapid in vivo screens confirmed $\geq 2 \log 10$ CFU reductions in the lungs of both gamma interferon knockout mice and immunocompetent C57BL/6 mice at a dose of $100 \mathrm{mg} / \mathrm{kg}^{44}$ Long-term in vivo screens further demonstrated that at $100 \mathrm{mg} / \mathrm{kg}$, pretomanid reduces the $\mathrm{CFU}$ in lungs and spleens of $\mathrm{C} 57 \mathrm{BL} / 6$ mice to the same extent as INH $(25 \mathrm{mg} / \mathrm{kg})$, gatifloxacin $(100 \mathrm{mg} / \mathrm{kg})$ and moxifloxacin $(100 \mathrm{mg} / \mathrm{kg})$. At lower doses, pretomanid (50 mg/kg), INH (10 mg/kg), and rifampin (10 mg/kg) each demonstrated comparable and persistent reductions in CFU over a 4 month treatment window; however, 3 months post-treatment all mice receiving pretomanid or INH relapsed, indicating a failure to achieve sterile cure as a single agent. ${ }^{45} \mathrm{~A}$ combination regimen including pretomanid (at 50 or $100 \mathrm{mg} / \mathrm{kg}$ ) with bedaquiline and an oxazolidinone (sutezolid or linezolid) led to CFU reductions a full order of magnitude lower than can be achieved with pretomanid alone, and complete or near complete sterilization was observed in some cases (TB Alliance, personal communication data). ${ }^{46,47}$

Initial estimates of pretomanid ( $40 \mathrm{mg} / \mathrm{kg})$ activity in the guinea pig model closely paralleled those observed in early mouse models showing near equivalent reduction in mycobacterium burden in the spleen and lung compared with isoniazid $(25 \mathrm{mg} / \mathrm{kg}){ }^{2}$ One additional investigation examined various drugs alone and in combination in the guinea pig model. ${ }^{48}$ In this study, distinctions between 3-drug regimens (vs dual or monotherapy) could be appreciated with the combination pretomanid, moxifloxacin, and pyrazinamide (PaMZ) demonstrating significantly greater reductions in CFU compared with rifampin, isoniazid, pyrazinamide (RHZ); however, by 2 months both groups were culture negative. Among 2-drug regimens no clear distinctions were observed. $^{48}$

In an attempt to understand the relationship between pretomanid exposure and response, time-kill kinetics of 
pretomanid against $\mathrm{MTb} \mathrm{H} 37 \mathrm{Rv}$ under aerobic conditions were evaluated at concentrations ranging from 0.12 to 2.0 $\mu \mathrm{g} / \mathrm{mL}$ (TB Alliance, personal communication data). Based on these experiments, pretomanid appears to exhibit both concentration- and time-dependent bactericidal activity. Though only 2 concentrations were tested under anaerobic conditions ( 3 and $12.5 \mu \mathrm{g} / \mathrm{mL}$ ), a similar observation was noted (TB Alliance, personal communication data). Dose fractionation studies were also conducted in BALB/c mouse models. ${ }^{49}$ These studies attempted to disassociate interdependent pharmacokinetic surrogates [ie, maximum concentration to MIC ratio (Cmax/MIC), area-under-thecurve to MIC ratio (AUC/MIC), and percent of time spent above the MIC (\%T>MIC)] so as to identify the measure most closely associated with bactericidal activity. In total, 31 different pretomanid dosing regimens were examined. Among the surrogates evaluated, \% $>$ MIC demonstrated the strongest association with CFU counts in the lung $\left(\mathrm{r}^{2}=\right.$ $0.87)$, followed by AUC/MIC $\left(r^{2}=0.60\right)$. Only a weak association was observed with Cmax/MIC $\left(r^{2}=0.17\right){ }^{49}$ Using these models and pharmacokinetic data from Phase I studies, the investigators ran simulations exploring putative $\% \mathrm{~T}>\mathrm{MIC}$ values for pretomanid at MICs ranging from 0.03125 to $0.25 \mu \mathrm{g} / \mathrm{mL}$. At the labeled $200 \mathrm{mg}$ dose, pretomanid concentrations are predicted to spend over two-thirds of the dosing interval above the $\mathrm{MIC}_{50}$. Modeling and simulation have also been used to explore the efficacy of pretomanid-containing regimens other than the FDA-approved BPaL. Pretomanid plus moxifloxacin appeared effective at eliminating MTB burden in vitro. ${ }^{50,51}$ In a recent exposure-response model-based meta-analysis in mice, the addition of pretomanid to rifampicin and bedaquiline reduced the simulated bacterial activity of bedaquiline in multi-drug regimens; however, predicted MICs were still within the range of susceptibility. ${ }^{52}$

\section{Clinical Microbiology}

Four clinical studies evaluated the early bactericidal activity (EBA) of pretomanid in humans after 14 days of dosing demonstrating that pretomanid was non-inferior to an isoniazid, rifampin, pyrazinamide, ethambutol (HRZE) containing regimen (Table 1). Two additional studies examined the EBA of pretomanid containing regimens after 8 weeks of dosing and suggested that these outperformed HRZE at 8 weeks (Table 1). Notably, none of the regimens evaluated reflect the FDA approved $\mathrm{BPaL}$ regimen. It should be noted that the data provided in the table reflect those submitted as part of the NDA and the numbers are not entirely consistent with the data presented on the ClinicalTrials.gov website or in the related study publications. ${ }^{53-56}$ Per the sponsor, these discrepancies are due to a change in the method used for calculating EBA [personal communication K. Schostack]. The trends in the data remain unchanged and the conclusions drawn are largely unaffected. Recent modeling and simulation studies using data from these early phase clinical trials (eg, NC-002, NC-005, NC-006, Nix-TB) suggest that the approved pretomanid dosing regimen (200 mg daily with food) provides optimal exposure (eg, \% $\%>$ MIC) compared with alternate dosing schemes to meet efficacy endpoints even after assuming wide inter-individual variability in drug disposition..$^{57,58}$

\section{Pharmacology and Toxicology}

The physicochemical properties of pretomanid are an important determinant of its pharmacologic and toxicologic effects. Pretomanid is a highly lipophilic compound with low solubility. ${ }^{59}$ Based on the partition coefficient, pretomanid is predicted to diffuse across lipid membranes with minimal difficulty.

\section{Absorption}

The absolute bioavailability is suggested to be less than $50 \%$ based on oral and IV administration in male cynomolgus monkeys. $\mathrm{C}_{\max }$ demonstrates wide interindividual variability (\%CV 127) in healthy volunteers ${ }^{60}$ with $T_{\max }$ at 4-5 hours. After a single oral dose of 50-750 mg given to healthy volunteers, systemic exposure increased to approximately $55-80 \%$ of what would be expected if truly dose proportional. A plateau in systemic exposure was seen after single doses $\geq 1000 \mathrm{mg}$. After multiple doses, pretomanid displayed an accumulation factor of $\sim 2$. $\mathrm{T}_{\max }$ remained 4-5 hours across single or multiple doses. ${ }^{61}$

Two randomized, cross-over studies have been conducted in healthy volunteers to assess the effect of food on the pharmacokinetics of pretomanid. In contrast to non-human primates, humans have markedly higher exposures to pretomanid if administered in the fed state compared with the fasted state. In the first study, a $1000 \mathrm{mg}$ dose was explored administered as $5 \times 200 \mathrm{mg}$ tablets. In the second study, $50 \mathrm{mg}$ and $200 \mathrm{mg}$ doses were examined each administered as an individual $50 \mathrm{mg}$ or $200 \mathrm{mg}$ tablet. ${ }^{62}$ Pretomanid was administered after a 10-hour fast or a high-calorie, high-fat meal with an 8-day washout between doses. At every dose (50, $200,1000 \mathrm{mg}$ ), pretomanid exposures were elevated when co-administered with a high-fat meal. The relative increase in 
Table I Clinical Studies Evaluating Early Bactericidal Activity (EBA) of Pretomanid in Humans

\begin{tabular}{|c|c|c|c|c|c|}
\hline \multirow{2}{*}{$\frac{\text { Study }}{\text { (Objective) }}$} & \multirow{2}{*}{$\begin{array}{l}\text { Resistance } \\
\text { Phenotype }\end{array}$} & \multirow[t]{2}{*}{ Regimen } & \multirow[t]{2}{*}{$\mathbf{n}$} & \multicolumn{2}{|c|}{ Rate of Change in Sputum } \\
\hline & & & & CFU & TTP \\
\hline CL-0I0 (I4d EBA) & DS-TB & $\begin{array}{l}\mathrm{Pa}_{50} \\
\mathrm{~Pa}_{100} \\
\mathrm{~Pa}_{150} \\
\mathrm{~Pa}_{200} \\
\mathrm{HRZE} \mathrm{E}_{\mathrm{BW}}\end{array}$ & $\begin{array}{l}15 \\
15 \\
15 \\
16 \\
8\end{array}$ & $\begin{array}{l}0.060(0.069) \\
0.099(0.069) \\
0.106(0.085) \\
0.111(0.074) \\
0.141(0.054)\end{array}$ & $\begin{array}{l}2.78(2.73) \\
5.82(3.08) \\
4.55(3.76) \\
5.10(3.25) \\
11.10(4.78)\end{array}$ \\
\hline CL-007 (I4d EBA) & DS-TB & $\begin{array}{l}\mathrm{Pa}_{200} \\
\mathrm{~Pa}_{600} \\
\mathrm{~Pa}_{1000} \\
\mathrm{~Pa}_{1200} \\
\text { HRZE }_{\mathrm{BW}}\end{array}$ & $\begin{array}{l}15 \\
15 \\
16 \\
15 \\
8\end{array}$ & $\begin{array}{l}0.121(0.067) \\
0.119(0.044) \\
0.106(0.089) \\
0.127(0.084) \\
0.133(0.061)\end{array}$ & $\begin{array}{l}3.61(3.09) \\
4.45(3.16) \\
5.94(3.84) \\
5.82(3.39) \\
9.71(4.76)\end{array}$ \\
\hline NC-00I (I4d EBA) & DS-TB & $\begin{array}{l}\mathrm{Pa}_{200} \mathrm{M}_{400} \mathrm{Z}_{\mathrm{BW}} \\
\mathrm{Pa}_{200} \mathrm{Z}_{\mathrm{BW}} \\
\mathrm{B}_{700>400} \mathrm{~Pa}_{200} \\
\mathrm{~B}_{700>400} \mathrm{Z}_{\mathrm{BW}} \\
\mathrm{B}_{700>400} \\
\mathrm{HRZ} \mathrm{E}_{\mathrm{BW}}\end{array}$ & $\begin{array}{l}15 \\
15 \\
15 \\
15 \\
15 \\
10\end{array}$ & $\begin{array}{l}0.233(0.128) \\
0.153(0.040) \\
0.114(0.050) \\
0.134(0.102) \\
0.065(0.068) \\
0.140(0.094)\end{array}$ & $\begin{array}{l}\text { I8.48 (22.58) } \\
8.81(3.47) \\
5.86(2.79) \\
9.97(6.99) \\
5.41(3.52) \\
\text { II.84 (3.93) }\end{array}$ \\
\hline NC-003 (I4d EBA) & DS-TB & $\begin{array}{l}\mathrm{B}_{400>200} \mathrm{~Pa}_{200} \mathrm{Z}_{1500} \mathrm{C}_{300>100} \\
\mathrm{~B}_{400>200} \mathrm{~Pa}_{200} \mathrm{Z}_{1500} \\
\mathrm{~B}_{400>200} \mathrm{~Pa}_{200} \mathrm{C}_{300>100} \\
\mathrm{~B}_{400>200} \mathrm{Z}_{1500} \mathrm{C}_{300>100} \\
\mathrm{Z}_{1500} \\
\mathrm{C}_{300>100} \\
\text { HRZE }\end{array}$ & $\begin{array}{l}15 \\
15 \\
15 \\
15 \\
15 \\
15 \\
15\end{array}$ & $\begin{array}{l}0.111[0.037,0.184] \\
0.167[0.078,0.256] \\
0.076[0.007,0.147] \\
0.119[0.031,0.211] \\
0.037[-0.025,0.100] \\
0.017[-0.086,0.055] \\
0.151[0.070,0.231]\end{array}$ & $\begin{array}{l}0.026[0.017,0.035] \\
0.029[0.017,0.035] \\
0.017[0.010,0.023] \\
0.021[0.014,0.030] \\
0.008[0.003,0.014] \\
-0.001[-0.006,0.005] \\
0.027[0.021,0.032]\end{array}$ \\
\hline NC-002 (8 wk trial) & DS-TB or MDR-TB & $\begin{array}{l}P_{100} M_{400} Z_{1500} \\
P_{200} M_{400} Z_{1500} \\
H_{R Z E_{B W}} \\
P_{200} M_{400} Z_{1500}\end{array}$ & $\begin{array}{l}60 \\
62 \\
59 \\
26\end{array}$ & $\begin{array}{l}0.133[0.109,0.155] \\
0.155^{*}[0.133,0.178] \\
0.112[0.093,0.131] \\
0.117[0.070,0.174]\end{array}$ & $\begin{array}{l}0.020[0.015,0.025] \\
0.020[0.016,0.024] \\
0.017[0.013,0.021] \\
0.015[-0.001,0.031]\end{array}$ \\
\hline NC-005 (8 wk trial) & DS-TB or MDR-TB & $\begin{array}{l}\mathrm{B}_{200} \mathrm{~Pa}_{200} \mathrm{Z}_{1500} \\
\mathrm{~B}_{400>200} \mathrm{~Pa}_{200} \mathrm{Z}_{1500} \\
\mathrm{HRZE}_{\mathrm{BW}} \\
\mathrm{B}_{200} \mathrm{~Pa}_{200} \mathrm{M}_{400} \mathrm{Z}_{1500}\end{array}$ & $\begin{array}{l}60 \\
59 \\
61 \\
60\end{array}$ & $\begin{array}{l}0.109[0.097,0.121] \\
0.123[0.109,0.139] \\
0.116[0.106,0.127] \\
0.156^{*}[0.125,0.198]\end{array}$ & $\begin{array}{l}5.17^{*}[4.61,5.77] \\
4.87^{*}[4.31,5.47] \\
4.04[3.67,4.42] \\
5.18^{*}[4.60,5.83]\end{array}$ \\
\hline
\end{tabular}

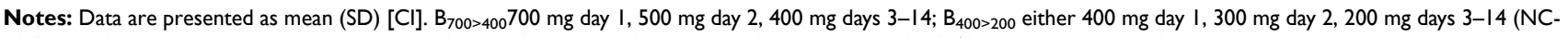
003) or $400 \mathrm{mg}$ days I-14, $200 \mathrm{mg}$ days I5-56 (NC-005); $C_{300>100} 300 \mathrm{mg}$ day I-3, $100 \mathrm{mg}$ days 4-I4. *Statistically different from HRZE.

Abbreviations: $\mathrm{Pa}$, pretomanid; $\mathrm{B}$, bedaquiline; $\mathrm{M}$, moxifloxacin; $\mathrm{Z}$, pyrazinamide; $\mathrm{C}$, clofazimine; $\mathrm{H}$, isoniazid; $\mathrm{R}$, rifampicin; $\mathrm{E}$, ethambutol.

bioavailability gets disproportionately larger with increasing dose, likely accounted for by an overall reduction in bioavailability (less than proportional increase in exposure) at higher doses in the fasted state. Only nominal changes in Tmax and half-life were observed. Thus, at the labeled dose of $200 \mathrm{mg}$, average increases of $76 \%$ in Cmax and $88 \%$ in AUC can be expected. A recent study suggests that this increased exposure in the fed state may be leveraged to negate the reduction expected with co-administration of rifampin. ${ }^{63}$

\section{Distribution}

Pretomanid is distributed throughout the body $\left(\mathrm{V}_{\mathrm{d}} / \mathrm{F} 92-\right.$ 180 L) (TB Alliance, personal communication data) ${ }^{64}$ and enters the central nervous system. ${ }^{65}$ Pretomanid is moderately protein bound in human plasma, mainly to albumin, ranging from 86.3 to $86.5 \%{ }^{66}$ The ratio of pretomanid in blood to plasma was examined in two studies and found to be less than 1, suggesting a low potential for partitioning into red blood cells. Across three concentrations (2.5-10 
$\mu \mathrm{g} / \mathrm{mL}$ ), ratios ranged from $0.66-0.83 \mathrm{~Kb} / \mathrm{p}$ and $0.31-0.68$ $\mathrm{Ke} /{ }^{66}{ }^{66}$

\section{Metabolism}

Pretomanid undergoes phase I and phase II biotransformation by multiple metabolic pathways (eg, oxidation, nitro reduction, oxidative deamination, oxidative cleavage, glycine conjugation, glucuronidation ${ }^{66}$ ) resulting in numerous metabolites. The most abundant metabolite identified in primary human hepatocytes is the trifluoromethoxybenzoic acid glycine conjugate; however, very little drug was transformed in this in vitro study (5-8\%) as compared with the extensive biotransformation seen in humans $(<1 \%$ unchanged in urine).

Among the cytochromes P450 (CYP), CYP3A4 appears to account for up to $20 \%$ of pretomanid biotransformation, a contribution that is abolished in the presence of the strong CYP3A4 inhibitor, ketoconazole. Other microsomal enzymes may contribute to pretomanid metabolism, although studies in recombinant enzymes suggest that CYP2C9, CYP2C19, and CYP2D6 play a negligible role. ${ }^{66}$ Clearance may be saturable at high concentrations above those expected with labeled dosing $(>600 \mathrm{mg} /$ daily), ${ }^{60}$ and no data are yet available for individuals with impaired liver function, though that study is forthcoming as requested by the FDA.

With respect to drug-drug interaction potential, the ability of pretomanid to inhibit phase I metabolic pathways, directly and in a time-dependent manner, has been investigated. In vitro, pretomanid demonstrates the potential to directly inhibit CYP3A4/5 up to $91 \%{ }^{66}$ at concentrations in excess of those observed with routine dosing. A downward shift in $\mathrm{IC}_{50}$ under time-dependent conditions is seen for several drug-metabolizing enzymes and suggests a potential for CYP3A, CYP2C8, and CYP2C19 mediated drug-drug interactions. In contrast, the recorded $\mathrm{IC}_{50}$ values for CYP1A2 and CYP2D6 (>100 $\left.\mu \mathrm{M}\right)$ suggest that no clinically significant inhibition is expected for their substrates. The potential for pretomanid to induce phase I DME was also evaluated in primary human hepatocytes from 4 individual donors. CYP3A4 and CYP2C9 induction appears to be negligible at clinically relevant concentrations. The large degree of variability for CYP2E1 makes the findings inconclusive. CYP2D6, CYP2A6, and CYP2C19 have not been tested. ${ }^{66}$

A limited number of healthy volunteer studies are available exploring the in vivo impact of the potential for these drug-drug interactions identified in vitro. One study details the impact of CYP3A inducers (efavirenz, lopinavir/ritonavir, rifampin) on the disposition of pretomanid ${ }^{67}$ and two studies examined the impact of pretomanid on CYP3A4 substrates (midazolam, efavirenz, lopinavir/ ritonavir). ${ }^{67,68}$ In healthy volunteers, coadministration of pretomanid with the CYP3A4 inducer rifampin reduces pretomanid exposure by over $50 \%$. The CYP3A4 inducer efavirenz reduces pretomanid exposures by $\sim 30 \%$ whereas exposures drop by less than $20 \%$ when co-administered with the weak inducer lopinavir/ritonavir. When the impact of pretomanid is measured on co-administered CYP3A substrates, there is no appreciable effect on efavirenz or lopinavir/ritonavir. At a dose twice that recommended by the FDA, modest induction of midazolam is observed as evidenced by both a reduction in the parent compound and an increase in the formation of its CYP3A mediated metabolite, 1'-hydroxy midazolam. The clinical impact of this observation is likely limited and the FDA concludes that pretomanid can be administered with other CYP3A substrates. However, co-administration should be avoided with rifampin, efavirenz, or other moderate to strong inducers of CYP3A4.

Two additional studies in rats examined the disposition of pretomanid, moxifloxacin, pyrazinamide, and darunavir alone and in combination. ${ }^{69,70}$ Darunavir demonstrates strong induction of pretomanid which likely occurs at the level of CYP3A. In contrast, the mechanism behind the moderate increase in moxifloxacin and pretomanid exposures that are observed in rats when the drugs are coadministered as $\mathrm{PaMZ}$ is unclear. Enhanced bioavailability is a plausible mechanism for pretomanid but would not explain the increase in exposure for moxifloxacin which is well absorbed in the absence of other medications. Whether linearity is compromised at the doses studied, or this reflects a species-specific interaction is unclear.

\section{Excretion}

In healthy volunteers, approximately $53 \%$ of the total dose is recovered in the urine, of which very little is unchanged drug (1\%). Nearly $38 \%$ of the total dose is recovered in feces. The elimination half-life is $\sim 17$ hours regardless of food conditions. Data are not currently available for individuals with impaired renal function, but such studies have been requested by the FDA and are in progress. A steady state dose escalation study of pretomanid identified a relationship between trough concentrations of the drug and increased circulating serum creatinine levels $\left(\mathrm{R}^{2}=\right.$ $0.59)$ with a subsequent decline after discontinuation of 
the drug. In contrast, there was no consistent change in blood urea nitrogen levels. ${ }^{61}$ The authors subsequently attempted to explore the mechanism behind these findings, specifically whether there were corresponding increases in protein catabolism or reductions in renal function. ${ }^{71}$ The follow-up study suggests that these changes are likely the result of inhibition of creatinine secretion at the level of the renal proximal tubule.

\section{Transport}

In considering transport, pretomanid does not appear to be a substrate for OAT1, OAT3, OCT2, OATP1B1, OATP1B3, MATE1, MATE2-K, BCRP or P-gp based on in vitro transporter assays in MDCK-II cells and MDCK_MDR1 cells. ${ }^{66}$ Inhibition by pretomanid of the aforementioned transporters was also evaluated in vitro. At clinically relevant concentrations, pretomanid inhibits the renal tubular uptake transporter OAT3 which could reduce the clearance of substrate drugs (eg, antibiotics, antivirals, $\mathrm{H}_{2}$-receptor antagonists, diuretics, NSAIDs, statins, uricosurics, and methotrexate). Inhibition of MATE2$\mathrm{K}$ at clinically relevant concentrations is less likely while no inhibition is expected for OAT1, OCT1, OCT2, OAT1B1, OATP1B3, BCRP, BSEP, P-gp, and MATE1 (TB Alliance, personal communication data). ${ }^{66}$

\section{Toxicology}

The majority of data regarding potential toxic effects of pretomanid comes from in vitro and preclinical studies. No mutagenic or clastogenic effects of pretomanid were detected in Ames assays (5000 $\mu \mathrm{g} /$ plate), Chinese hamster ovary cell assays (up to $1000 \mu \mathrm{g} / \mathrm{mL}$ ), in vitro mouse lymphoma assays (up to $500 \mu \mathrm{g} / \mathrm{mL}$ ), and in vivo mouse micronucleus assays (up to $2000 \mathrm{mg} / \mathrm{kg} /$ day). However, the hydroxy imidazole metabolite (M50) which accounts for $\sim 6 \%$ of the human pretomanid exposure, was positive on Ames testing. ${ }^{66}$ No significant increase in the incidence of lung tumors, hemangiosarcoma, nonvascular tumors, and other tumors was found after 26-weeks of daily pretomanid dosing in TG.rasH2 mice (TB Alliance, personal communication data). A post-marketing 2-year carcinogenicity study in rats has recently been completed and is under regulatory review at the time of this publication. Long-term safety data in humans are not yet available but will shed light on carcinogenicity and mutagenicity with clinical use of pretomanid.

At exposure most relevant to labeled dosing in humans, organ specific safety signals from animal studies demonstrate the potential for hepatic, ophthalmologic and reproductive toxicity (TB Alliance, personal communication data). ${ }^{66} \mathrm{~A}$ dose-dependent increase in liver weight without histopathological findings was seen in non-human primates and the no-observed-adverse-eventlevel (NOAEL) was set at $1.5 \mathrm{x}$ human exposure. Murine studies demonstrated hepatic hypertrophy and limited liver transaminase elevations with NOAEL at 7x human exposure. Mixed ophthalmological findings in nonhuman primates led to NOAEL of $100 \mathrm{mg} / \mathrm{kg} / \mathrm{day}$ ( $2.6 \mathrm{x}$ human exposure). In rats, $20 \%$ developed cataracts at various dosing schemes and ultimately the NOAEL was set to $30 \mathrm{mg} / \mathrm{kg} /$ day $(\sim 1.5 \mathrm{x}$ human exposure); however, cataracts were not seen in monkeys at 12x human exposure. Neurological findings, eg, seizures and ataxia, were present in short-term high dose studies (eg, 2 weeks at $1000 \mathrm{mg} / \mathrm{kg} /$ day) in non-human primates, but rarely present in long-term studies. The NOAEL was set at $50 \mathrm{mg} / \mathrm{kg} /$ day $(\sim 1.3 \mathrm{x}$ human exposure).

QTc prolongation is not expected at labeled dosing. A dose-dependent increase in QTc was observed in nonhuman primates with NOAEL set at $150 \mathrm{mg} / \mathrm{kg}$ (4x human exposure). This finding appears consistent with an in vitro cardiac safety screen (hERG current inhibition) demonstrating an $\mathrm{IC}_{50}$ equivalent to $3 \mathrm{x}_{\max }$ in plasma at labeled doses. One study used modeling and simulation to evaluate the impact of pretomanid alone and in combination $(\mathrm{BPaL})$ on QTc interval using data from 8 clinical trials submitted in the NDA. Although a positive exposure-response relationship was found, $<10 \mathrm{~ms}$ increase is expected at maximum plasma concentrations seen with labeled dosing. ${ }^{72}$

According to initial FDA review documents, the testicular toxicity in monkeys was set to $50 \mathrm{mg} / \mathrm{kg}$; ${ }^{66}$ however, more recent data from the sponsor report an NOAEL of $100 \mathrm{mg} / \mathrm{kg} /$ day ( 2.6x human exposure) with no abnormal testicular findings after 9 months of dosing in monkeys. The NOAEL for maternal and embryo-fetal effects in rats was $10 \mathrm{mg} / \mathrm{kg}$ and $30 \mathrm{mg} / \mathrm{kg}$, respectively and in rabbits was $10 \mathrm{mg} / \mathrm{kg}$ and $60 \mathrm{mg} / \mathrm{kg}$, respectively. In lactating dams treated with a regimen thought to be equivalent to human exposure, a single point estimate of pretomanid revealed a higher concentration in milk $(1.6 \mu \mathrm{g} / \mathrm{mL})$ compared with plasma $(1.1 \mu \mathrm{g} / \mathrm{mL})$. At regimens equivalent to $2-4 \mathrm{x}$ human exposure, concentrations in milk were $59-68 \%$ of plasma concentrations. These data merit discussions of off-label use in children and pregnant females. No lactation data are yet available in humans and alternative therapy may be considered until more is known. ${ }^{73}$ The FDA has required a post- 
marketing human semen study and, once available, data can inform clinical discussions with males of reproductive age.

Shared decision-making regarding treatment of MDR/ XR-TB with a pretomanid-containing regimen should involve discussion of the potential pretomanid toxicity based on limited animal data weighed carefully against the risk of untreated TB infection. For pregnant adults specifically, it is important to acknowledge the known adverse maternal and fetal outcomes associated with untreated tuberculosis ${ }^{74}$ while balancing the unknown teratogenic and developmental effects of pretomanid. Because of the lack of data, the WHO does not currently recommend use of pretomanid in pregnancy.

\section{Efficacy and Safety}

For the initial review of the new drug application (NDA), the FDA assessed interim data from the NIX-TB trial for participants who had completed the 6-month posttreatment follow up or died $(n=45)$. The efficacy data in the NDA were updated throughout the review and based primarily on $n=81$ participants available by an interim data cut-off date. Data from all participants who received pretonamid $(\mathrm{n}=109)$ were available prior to full approval. ${ }^{66}$ The NIX-TB trial $(n=109)$ enrolled participants with XDR-TB (65\%) and MDR-TB (35\%). Fifty-one percent of the participants were $\mathrm{HIV}+$. In the intention-to-treat (ITT) analysis, favorable outcomes were $90 \%$ and $88 \%$ at 6 months and 24 months, respectively, and not influenced by sex and HIV status (Table 2). ${ }^{75,76}$ A recent case study describes the successful treatment of MDR-TB using a lower linezolid dynamic dosing based on an exposure target of $600 \mathrm{mg} / \mathrm{d}$ vs $1200 \mathrm{mg} / \mathrm{d}$ in combination with pretamonid and bedaquiline. ${ }^{77}$ Similar regimens are currently being evaluated in the ZeNix trial. Table 3 lists ongoing trials for pretomanid-containing regimens, some of which include pediatric patients. No efficacy data are yet available for these trials at the time of this review.

In the completed NIX-TB trial, all 109 participants (100\%) experienced at least 1 treatment emergent adverse event (TEAE), nearly all of which were considered related to study drug (99\%). In 19 subjects (17.4\%) 36 serious TEAEs were reported, with infection being most prominent (11 events). One event each of mild optic neuropathy and elevated transaminases was reported. ${ }^{75}$ No grade $\geq 3$ ophthalmic TAEs were reported and there was no evidence of cataracts detected by slit lamp examinations associated with pretomanid. ${ }^{75}$ All surviving participants were able to complete the full course of therapy with some interruptions due to adverse events, and no adverse-event related withdrawal. The STAND trial, which evaluated pretomanid, moxifloxacin, and pyrazinamide compared with standard treatment (HRZE), found more than a 2-fold higher rate in gastrointestinal (nausea, vomiting, diarrhea) and pulmonary (pleuritic pain, hemoptysis, URI) adverse

Table 2 Efficacy of Pretomanid-Containing Regimens

\begin{tabular}{|c|c|c|c|c|c|c|}
\hline \multirow[t]{2}{*}{ Trial } & \multirow[t]{2}{*}{ Regimen } & \multirow[t]{2}{*}{ Phenotype } & \multicolumn{2}{|c|}{ mITT at 6 Months } & \multicolumn{2}{|c|}{$\mathbf{P P}$} \\
\hline & & & Favorable & Unfavorable & Favorable & Unfavorable \\
\hline \multirow[t]{2}{*}{ NIX-TB^ } & \multirow{2}{*}{$\begin{array}{l}\mathrm{Pa}_{200} \mathrm{QD}, \mathrm{B}_{400} \mathrm{QD} \times 2 \text { weeks then } \mathrm{B}_{200} 3 \times / \text { week, } \\
\mathrm{L}_{1200} \mathrm{QD} \times 30 \text { weeks }\end{array}$} & $X D R(n=7 I)$ & $63 *(90 \%)$ & $7(10 \%)$ & $62(91 \%)$ & $6(9 \%)$ \\
\hline & & $\begin{array}{l}\text { TI/NR MDR } \\
(n=38)\end{array}$ & 35 (95\%) & $2(5 \%)$ & $35(95 \%)$ & $2(5 \%)$ \\
\hline STAND & $\mathrm{Pa}_{100} \mathrm{M}_{400} \mathrm{Z}_{1500} \times 17$ weeks & DS-TB & $38(66.7 \%)$ & 19 (33.3\%) & 38 (73.1\%) & 14 (26.9\%) \\
\hline STAND & $\mathrm{Pa}_{200} \mathrm{M}_{400} \mathrm{Z}_{1500} \times 17$ weeks & DS-TB & $46(75.4 \%)$ & $15(24.6 \%)$ & $46(80.7 \%)$ & II (19.3\%) \\
\hline STAND & $\mathrm{Pa}_{200} \mathrm{M}_{400} \mathrm{Z}_{1500} \times 26$ weeks & DS-TB & $43(76.8 \%)$ & $13(23.2 \%)$ & 43 (91.5\%) & $4(8.5 \%)$ \\
\hline STAND & $\mathrm{H}_{75} \mathrm{R}_{150} \mathrm{Z}_{400} \mathrm{E}_{275} \times 8$ wks; $\mathrm{H}_{75} \mathrm{R}_{150}$ wks 9 to 26 & DS-TB & $52(86.7 \%)$ & 8 (13.3\%) & $52(98.1 \%)$ & I (I.9\%) \\
\hline STAND & $\mathrm{Pa}_{200} \mathrm{M}_{400} \mathrm{Z}_{1500} \times 26$ weeks & MDR-TB & $10(90.9 \%)$ & I (9.1\%) & $\begin{array}{c}10 \\
(100.0 \%)\end{array}$ & $0(0.0 \%)$ \\
\hline
\end{tabular}

Notes: *The following categorical variables had no appreciate impact on mITT: HIV status, linezolid regimen (600 mg BID or I200 QD), age (above or below median), gender, race (black vs white/other), cavitation, TTP at baseline from MGIT (above or below median). ^NIX-TB- Two exclusions in mITT resulting in total $\mathrm{n}=\mathrm{I07}$ (non-TB related death in follow up and lost to follow up after end of treatment). Two additional exclusions in PP resulting in total $n=105$ (one inadequate amount of drug and one withdrawn not for treatment failure).

Abbreviations: mITT, modified intention to treat; PP, per protocol. 
Table 3 Ongoing Clinical Trials of Pretomanid-Containing Regimens for TB

\begin{tabular}{|c|c|c|c|c|c|c|c|}
\hline Trial & Design & $\begin{array}{l}\text { Drug } \\
\text { Regimens }\end{array}$ & Comparator & Population & $\begin{array}{l}\text { Primary } \\
\text { Outcome(s) }\end{array}$ & $\begin{array}{l}\text { Expected/ } \\
\text { Reported } \\
\text { Completion } \\
\text { Date }\end{array}$ & Clinical Trial \\
\hline ZeNix & $\begin{array}{l}\text { Multicenter, } \\
\text { partially- } \\
\text { blinded (Z } \\
\text { only), } \\
\text { randomized, } \\
\text { Phase III }\end{array}$ & $\begin{array}{l}\mathrm{BPaL}_{1200 \times 26} \times 26 \\
\mathrm{BPaL}_{1200 \times 9} \times 9 \mathrm{k} \\
\mathrm{BPaL}_{600 \times 26 w k} \\
\mathrm{BPaL}_{600 \times 9 w k}\end{array}$ & $n / a$ & $\begin{array}{l}\text { MDR-TB, } \\
\text { XDR-TB or } \\
\text { pre-XDR- } \\
\text { TB, target } \\
\text { enrollment } \\
n=180 ; \geq 14 \\
\text { yrs }\end{array}$ & $\begin{array}{l}\text { Incidence of } \\
\text { bacteriologic failure or } \\
\text { relapse or clinical failure } \\
\text { through follow up until } \\
26 \text { weeks after the end } \\
\text { of treatment }\end{array}$ & $|2 / 202|$ & NCT03086486 \\
\hline SimpliciTB & $\begin{array}{l}\text { Multicenter, } \\
\text { open-label, } \\
\text { partially } \\
\text { randomized, } \\
\text { phase llc }\end{array}$ & BPaMZ & HRZE or HR & $\begin{array}{l}\text { DS-TB and } \\
\text { DR-TB, } \\
n=455 ; \geq 18 \\
\text { yrs }\end{array}$ & $\begin{array}{l}\text { Time to culture } \\
\text { conversion to negative } \\
\text { status over } 8 \text { weeks }\end{array}$ & $4 / 2020$ & NCT0333862I \\
\hline $\begin{array}{l}\text { TB- } \\
\text { PRACTECAL }\end{array}$ & $\begin{array}{l}\text { Multicenter, } \\
\text { open label, } \\
\text { multi-arm, } \\
\text { randomized, } \\
\text { controlled, } \\
\text { Phase II-III } \\
\text { trial }\end{array}$ & $\begin{array}{l}\mathrm{BPaML} \text { or } \\
\mathrm{BPaCL} \text { or } \mathrm{BPaL}\end{array}$ & $\begin{array}{l}\text { Locally } \\
\text { accepted SOC }\end{array}$ & $\begin{array}{l}\text { MDR-TB, } \\
\text { target } \\
\text { enrollment } \\
n=630 ; \geq 15 \\
\text { yrs }\end{array}$ & $\begin{array}{l}\text { Stage I: \% culture } \\
\text { conversion in liquid } \\
\text { media at } 8 \text { wks } \\
\text { Stage I: \%treatment } \\
\text { discontinuation for any } \\
\text { reason } \\
\text { Stage } 2: \% \text { unfavorable } \\
\text { outcome }\end{array}$ & Early 2023 & NCT02589782 \\
\hline
\end{tabular}

Abbreviations: B, bedaquiline; C, clofazimine; DR-TB, drug resistant tuberculosis; DS-TB, drug susceptible tuberculosis; E, ethambutol; H, isoniazid; L, linezolid; M, moxifloxacin; MDR-TB, multidrug resistant tuberculosis; Pa, pretomanid; R, rifampicin; SOC, standard of care; XDR-TB, extensively resistant tuberculosis; Z, pyrazinamide.

events. Transaminase elevations along with the elevation of other LFTs were seen with moderate frequency among the non-serious AEs but at a rate comparable to HRZE. Three hepatotoxicity associated deaths initially prompted study suspension, but the study was allowed to resume after independent review by the drug safety monitoring committee. Overall, a higher rate of unfavorable outcomes for the primary measure compared with HRZE and failed non-inferiority criterion prompted early termination of the STAND trial. ${ }^{78}$

Safety data from ongoing trials (Table 3 ) are not yet publicly available. A recent Phase $2 \mathrm{~b}$ study in drugsusceptible or rifampin-resistant TB found that both pretomanid regimens outperformed standard therapy (HRZE) in the primary outcome, but also had higher rates of discontinuation due to adverse events ( $8-10 \%$ vs $3 \%)$. Serious adverse events occurred in two participants (3\%) receiving $\mathrm{B}_{\text {load }} \mathrm{PaZ}$ and one participant $(2 \%)$ receiving HRZE. Preliminary efficacy and adverse event data from this Phase $2 b$ study argue for continued study of $\mathrm{B}_{200} \mathrm{PaZ}$ in drug susceptible TB, particularly given its shorter duration of therapy and simplified dosing scheme (once daily). ${ }^{79}$

When the regimens are broadly combined and treatmentemergent non-serious adverse events are evaluated against a standard HRZE regimen (Table 4), neurologic and hepatic disturbances appeared to be more prevalent in the pretomanid containing regimens with arthralgias and gastrointestinal events more prevalent in the moxifloxacin containing regimens. Pretomanid alone $(\mathrm{n}=411)$ results in minimal liver toxicity with only $2.2 \%$ of individuals experiencing ALT or AST $>5 \times$ ULN, or total bilirubin $>2 \times$ ULN compared with $5.6-11.7 \%$ in pretomanid containing combination regimens and $6.5 \%$ in control or placebo regimens. These safety data suggest that liver toxicity is largely related to other anti-TB medications. ${ }^{80}$ Ascribing clinical trial related ADRs to pretomanid is confounded by the lack of long-term administration data for pretomanid alone. Headache may be attributed to pretomanid as it occurred more frequently in patients receiving pretomanid alone than control $(31.5 \%$ vs $22.9 \%)$ and occurred more frequently at higher pretomanid doses 
Table 4 Treatment Emergent Adverse Events for Various Regimens

\begin{tabular}{|c|c|c|c|c|c|}
\hline Regimen & \multirow[t]{2}{*}{$P a M Z n=\mid 48$} & \multirow[t]{2}{*}{ BPaZ $n=119$} & \multirow[t]{2}{*}{ BPaMZ $n=60$} & \multirow{2}{*}{$\begin{array}{c}\text { BPaL } n=109 \\
\text { NIX-TB }\end{array}$} & \multirow[t]{2}{*}{ HRZE $n=120$} \\
\hline Trial & & & & & \\
\hline Nausea & 30 (20.3\%) & $4(3.4 \%)$ & $5(8.3 \%)$ & 40 (36.7\%) & $8(6.7 \%)$ \\
\hline Vomiting & $18(12.2 \%)$ & 5 (4.2\%) & 7 (II.7\%) & 37 (33.9\%) & II (9.2\%) \\
\hline Diarrhea & $10(6.8 \%)$ & $4(3.4 \%)$ & $3(5 \%)$ & II (10.1\%) & $3(2.5 \%)$ \\
\hline Abdominal pain/dyspepsia & $9(6.1 \%)$ & & & 37 (34\%) & $3(2.5 \%)$ \\
\hline Decreased appetite & & & & $24(22.0 \%)$ & \\
\hline Abnormal weight loss & & & & II (10.1\%) & \\
\hline Liver disorder & $33(22.3 \%)$ & & & & $9(7.5 \%)$ \\
\hline Enzyme abnormality & $7(4.7 \%)$ & & & & $4(3.3 \%)$ \\
\hline ALT increased & & $8(6.7 \%)$ & $2(3.3 \%)$ & $10(9.2 \%)$ & $2(1.7 \%)$ \\
\hline AST increased & & $6(5 \%)$ & $3(5 \%)$ & $9(8.3 \%)$ & $3(2.5 \%)$ \\
\hline Amylase increased & & & $10(16.7 \%)$ & & I (0.8\%) \\
\hline GGT increased & & $2(1.7 \%)$ & $6(10 \%)$ & 19 (I7.4\%) & \\
\hline Anemia & & $5(4.2 \%)$ & I (I.7\%) & $40(36.7 \%)$ & \\
\hline Leukocytosis & $9(6.1 \%)$ & & & & $3(2.5 \%)$ \\
\hline Hyperkalemia or hyponatremia & $13(8.8 \%)$ & & & & $8(6.7 \%)$ \\
\hline Glucose abnormality & 9 (6.1\%) - hyper & & & 12 (1 I\%)-hypo & 3 (2.5\%)- hyper \\
\hline Hypoalbuminemia & $6(4.1 \%)$ & & & & $5(4.2 \%)$ \\
\hline Hyperuricemia & $42(28.4 \%)$ & $28(23.5 \%)$ & 27 (45\%) & & $26(21.7 \%)$ \\
\hline Dizziness & 15 (10.1\%) & $4(3.4 \%)$ & $\mathrm{I}(\mathrm{I} .7 \%)$ & & $5(4.2 \%)$ \\
\hline Headache & 14 (9.5\%) & & & $30(27.5 \%)$ & $2(1.7 \%)$ \\
\hline Peripheral sensory neuropathy* & & & & 76 (69.7\%) & \\
\hline Myalgia & & $7(5.9 \%)$ & $3(5 \%)$ & & I (0.8\%) \\
\hline Arthralgia & 38 (25.7\%) & $15(12.6 \%)$ & $13(21.7 \%)$ & & 17 (I4.2\%) \\
\hline Extremity or back pain & & $2(1.7 \%)$ & $4(6.7 \%)$ & 13 (II.9\%) & \\
\hline Acne & & & & 17 (I5.6\%) & \\
\hline Rash & & $3(2.5 \%)$ & I (I.7\%) & 17 (I5.6\%) & $2(1.7 \%)$ \\
\hline Pruritus generalized & & $8(6.7 \%)$ & $2(3.3 \%)$ & & $8(6.7 \%)$ \\
\hline Pruritis & $8(5.4 \%)$ & $5(4.2 \%)$ & $2(3.3 \%)$ & $16(14.7 \%)$ & $8(6.7 \%)$ \\
\hline Hemoptysis & & $4(3.4 \%)$ & $6(10 \%)$ & 14 (I2.8\%) & \\
\hline Pleuritic/non-cardiac chest pain & & & $6(10 \%)$ & 14 (I2.8\%) & \\
\hline UTI & & $2(1.7 \%)$ & $4(6.7 \%)$ & & $2(1.7 \%)$ \\
\hline
\end{tabular}

Notes: *Peripheral sensory neuropathy includes related codes (eg, neuropathy peripheral, paresthesia, hypoesthesia, peripheral motor neuropathy, burning sensation, hyporeflexia, peripheral sensorimotor neuropathy). 
( $45.6 \%$ in those receiving $>200 \mathrm{mg}$ ) (TB Alliance, personal communication data). No participants experienced arthralgia, hyperuricemia, hepatic enzyme elevations, hyperuricemia, hyperglycemia, somnolence, anemia, pruritic rash, photophobia, visual acuity disturbance, hematuria, proteinuria, breast disorders or death when taking pretomanid alone $(\mathrm{n}=122)$. Nausea occurred in $4.1 \%$ of pretomanid only group vs $6.1 \%$ in HRZE control group (TB Alliance, personal communication data). For individuals receiving the $\mathrm{BPaL}$ regimen, expert consensus suggests that hepatic enzyme elevations, lens disorders, dermatitis, GI upset, and severe cutaneous adverse reactions are more likely to be attributed to pretomanid rather than the other regimen components.

\section{Special Populations}

Current WHO recommendations highlight several special populations that deserve careful consideration before pretomanid use. No data are yet available for pretomanid use in children $<14$ years old, pregnant or lactating women, and medications with more established safety profiles are recommended for use at this time. Breastfeeding is not recommended when taking BPaL. For individuals living with HIV, concomitant antiretroviral therapy should be assessed and efavirenz avoided if possible due to reduced pretomanid exposure. Those taking zidovudine along with the $\mathrm{BPaL}$ regimen are at additive risk for peripheral nerve toxicity and myelosuppression from linezolid (rather than pretomanid). Although no data currently exist for pretomanid use in extrapulmonary $\mathrm{TB}$, treatment recommendations are unchanged for individuals with extrapulmonary manifestation of MDR-TB, including TB meningitis. Finally, for individuals with life-threatening extensive drug resistant TB that prevents the application of WHO guideline-based treatment, BPaL may be considered "as a last resort under prevailing ethical standards." ${ }^{, 81}$

\section{Conclusion}

Drug resistant MTB strains are difficult to treat, continue to emerge, and threaten global progress in combatting TB. ${ }^{81}$ The global clinical development pipeline for new anti-TB medicines has less than a dozen new drugs at the early stages of research. ${ }^{82}$ Since drug development is known to have particularly high attrition rates, only a few of these candidates may reach the market. This status quo and the fact that there were only three new medicines developed for TB treatment in the last 70 years make every emerging antiTB medicine an important and valuable asset.
Following bedaquiline and delamanid, pretomanid is the third recently approved medicinal agent for use in TB patients as part of the regimen also including bedaquiline and linezolid $(\mathrm{BPaL})$. This 6-month regimen brings a new perspective of shortening treatment for drugresistant TB and a shift from the currently recommended lengthy and difficult to tolerate and adhere to regimens, that usually last 9 to 20 months, to ones that are shorter and easier to implement. The BPaL regimen is conditionally recommended by WHO to be used under operational research framework that precludes its wider, programmatic use. ${ }^{81}$ However, the advent of the new medicine - pretomanid, as part of the $\mathrm{BPaL}$ regimen and the new guidance from WHO, have already stimulated a massive number of research studies that promise to bring additional evidence that may support broader and stronger recommendations on its use. Additionally, evaluation of cost-effectiveness of the BPaL is ongoing. ${ }^{83}$

In summary, pretomanid is part of a novel multi-drug regimen for MDR/XR-TB that allows for a shorter duration of therapy. Using shared decision making, counseling regarding benefits and risks may include the possibility of infertility through alterations in spermatogenesis and lack of safety and toxicology data in pregnant patients and breastfed infants. Additional forthcoming data will improve our understanding of the safety, efficacy, and use of pretomanid in TB.

\section{Acknowledgments}

The authors would like to thank Dan Everitt and Eugene Sun for kindly providing access to pretomanid data on file at TB Alliance.

\section{Disclosure}

The authors report no conflicts of interest in this work.

\section{References}

1. Global tuberculosis report. Geneva, Switzerland: World Health Organization; 2020. Available from: https://apps.who.int/iris/bit stream/handle/10665/336069/9789240013131-eng.pdf. Accessed March 15, 2021.

2. Stover CK, Warrener P, VanDevanter DR, et al. A small-molecule nitroimidazopyran drug candidate for the treatment of tuberculosis. Nature. 2000;405(6789):962-966. doi:10.1038/35016103

3. Thompson AM, Bonnet M, Lee HH, et al. Antitubercular nitroimidazoles revisited: synthesis and activity of the authentic 3-nitro isomer of pretomanid. ACS Med Chem Lett. 2017;8(12):1275-1280. doi:10.1021/acsmedchemlett.7b00356

4. Bahuguna A, Rawat DS. An overview of new antitubercular drugs, drug candidates, and their targets. Med Res Rev. 2020;40(1):263-292. doi:10.1002/med.21602 
5. Zhang J, Ba Y, Wang S, Yang H, Hou X, Xu Z. Nitroimidazolecontaining compounds and their antibacterial and antitubercular activities. Eur J Med Chem. 2019;179:376-388. doi:10.1016/j. ejmech.2019.06.068

6. Ang CW, Tan L, Sykes ML, et al. Antitubercular and antiparasitic 2-nitroimidazopyrazinones with improved potency and solubility. $J$ Med Chem. 2020;63(24):15726-15751. doi:10.1021/acs. jmedchem.0c01372

7. Moreno SN, Docampo R. Mechanism of toxicity of nitro compounds used in the chemotherapy of trichomoniasis. Environ Health Perspect. 1985;64:199-208. doi:10.1289/ehp.8564199

8. Singh R, Manjunatha U, Boshoff HI, et al. PA-824 kills nonreplicating Mycobacterium tuberculosis by intracellular NO release. Science. 2008;322(5906):1392-1395. doi:10.1126/science.1164571

9. Center for Drug Evaluaton and Research. Approval package for application number 212862Orig1s000. 2019.

10. Yuan Y, Barry CE 3rd. A common mechanism for the biosynthesis of methoxy and cyclopropyl mycolic acids in Mycobacterium tuberculosis. Proc Natl Acad Sci U S A. 1996;93(23):12828-12833. doi:10.1073/pnas.93.23.12828

11. Purwantini E, Mukhopadhyay B, Sem DS. Rv0132c of Mycobacterium tuberculosis encodes a coenzyme F420-dependent hydroxymycolic acid dehydrogenase. PLoS One. 2013;8(12): e81985. doi:10.1371/journal.pone.0081985

12. Baptista R, Fazakerley DM, Beckmann M, Baillie L, Mur LAJ. Untargeted metabolomics reveals a new mode of action of pretomanid (PA-824). Sci Rep. 2018;8(1):5084. doi:10.1038/s41598-01823110-1

13. Choi KP, Kendrick N, Daniels L. Demonstration that fbiC is required by Mycobacterium bovis BCG for coenzyme $\mathrm{F}(420)$ and FO biosynthesis. J Bacteriol. 2002;184(9):2420-2428. doi:10.1128/ JB.184.9.2420-2428.2002

14. Haver HL, Chua A, Ghode P, et al. Mutations in genes for the F420 biosynthetic pathway and a nitroreductase enzyme are the primary resistance determinants in spontaneous in vitro-selected PA-824resistant mutants of Mycobacterium tuberculosis. Antimicrob Agents Chemother. 2015;59(9):5316-5323. doi:10.1128/AAC.00308-15

15. Manjunatha UH, Boshoff H, Dowd CS, et al. Identification of a nitroimidazo-oxazine-specific protein involved in PA-824 resistance in Mycobacterium tuberculosis. Proc Natl Acad Sci U S A. 2006;103 (2):431-436. doi:10.1073/pnas.0508392103

16. Wen S, Jing W, Zhang T, et al. Comparison of in vitro activity of the nitroimidazoles delamanid and pretomanid against multidrug-resistant and extensively drug-resistant tuberculosis. Eur J Clin Microbiol Infect Dis. 2019;38(7):1293-1296. doi:10.1007/ s10096-019-03551-w

17. Kadura S, King N, Nakhoul M, et al. Systematic review of mutations associated with resistance to the new and repurposed Mycobacterium tuberculosis drugs bedaquiline, clofazimine, linezolid, delamanid and pretomanid. $J$ Antimicrob Chemother. 2020;75(8):2031-2043. doi:10.1093/jac/dkaa136

18. Bashiri G, Antoney J, Jirgis ENM, et al. A revised biosynthetic pathway for the cofactor $\mathrm{F}(420)$ in prokaryotes. Nat Commun. 2019;10(1):1558. doi:10.1038/s41467-019-09534-x

19. Rifat D, Li SY, Ioerger T, et al. Mutations in fbiD (Rv2983) as a novel determinant of resistance to pretomanid and delamanid in mycobacterium tuberculosis. Antimicrob Agents Chemother. 2020;65:1. doi:10.1128/AAC.01948-20

20. Sassetti CM, Boyd DH, Rubin EJ. Genes required for mycobacterial growth defined by high density mutagenesis. Mol Microbiol. 2003;48 (1):77-84. doi:10.1046/j.1365-2958.2003.03425.x

21. Sassetti CM, Rubin EJ. Genetic requirements for mycobacterial survival during infection. Proc Natl Acad Sci U S A. 2003;100 (22):12989-12994. doi:10.1073/pnas.2134250100
22. Zhang YJ, Ioerger TR, Huttenhower C, et al. Global assessment of genomic regions required for growth in Mycobacterium tuberculosis. PLoS Pathog. 2012;8(9):e1002946. doi:10.1371/journal. ppat. 1002946

23. Rengarajan J, Bloom BR, Rubin EJ. Genome-wide requirements for Mycobacterium tuberculosis adaptation and survival in macrophages. Proc Natl Acad Sci U S A. 2005;102(23):8327-8332. doi:10.1073/ pnas. 0503272102

24. Dutta NK, Mehra S, Didier PJ, et al. Genetic requirements for the survival of tubercle bacilli in primates. J Infect Dis. 2010;201 (11):1743-1752. doi:10.1086/652497

25. Lee BM, Harold LK, Almeida DV, et al. Predicting nitroimidazole antibiotic resistance mutations in Mycobacterium tuberculosis with protein engineering. PLoS Pathog. 2020;16(2):e1008287. doi:10.1371/journal.ppat.1008287

26. Gurumurthy M, Rao M, Mukherjee T, et al. A novel F(420) dependent anti-oxidant mechanism protects Mycobacterium tuberculosis against oxidative stress and bactericidal agents. Mol Microbiol. 2013;87(4):744-755. doi: $10.1111 / \mathrm{mmi} .12127$

27. Klitgaard RN, Ntokou E, Nørgaard K, et al. Mutations in the bacterial ribosomal protein 13 and their association with antibiotic resistance. Antimicrob Agents Chemother. 2015;59(6):3518-3528. doi:10.1128/ AAC.00179-15

28. Makafe GG, Cao Y, Tan Y, et al. Role of the Cys154Arg substitution in ribosomal protein L3 in oxazolidinone resistance in mycobacterium tuberculosis. Antimicrob Agents Chemother. 2016;60 (5):3202-3206. doi:10.1128/AAC.00152-16

29. Fujiwara M, Kawasaki M, Hariguchi N, Liu Y, Matsumoto M. Mechanisms of resistance to delamanid, a drug for Mycobacterium tuberculosis. Tuberculosis (Edinb). 2018;108:186-194. doi:10.1016/j. tube.2017.12.006

30. McGrath M, Gey van Pittius NC, van Helden PD, Warren RM, Warner DF. Mutation rate and the emergence of drug resistance in Mycobacterium tuberculosis. J Antimicrob Chemother. 2014;69 (2):292-302. doi:10.1093/jac/dkt364

31. Harper J, Skerry C, Davis SL, et al. Mouse model of necrotic tuberculosis granulomas develops hypoxic lesions. J Infect Dis. 2012;205(4):595-602. doi:10.1093/infdis/jir786

32. Li S-Y, Tasneen R, Tyagi S, et al. Bactericidal and sterilizing activity of a novel regimen with bedaquiline, pretomanid, moxifloxacin, and pyrazinamide in a murine model of tuberculosis. Antimicrob Agents Chemother. 2017;61(9):9. doi:10.1128/ AAC.00913-17

33. Tyagi S, Nuermberger E, Yoshimatsu T, et al. Bactericidal activity of the nitroimidazopyran PA-824 in a murine model of tuberculosis. Antimicrob Agents Chemother. 2005;49(6):2289-2293. doi:10.1128/ AAC.49.6.2289-2293.2005

34. Hurdle JG, Lee RB, Budha NR, et al. A microbiological assessment of novel nitrofuranylamides as anti-tuberculosis agents. J Antimicrob Chemother. 2008;62(5):1037-1045. doi:10.1093/jac/dkn307

35. Hartkoorn RC, Ryabova OB, Chiarelli LR, Riccardi G, Makarov V, Cole ST. Mechanism of action of 5-nitrothiophenes against Mycobacterium tuberculosis. Antimicrob Agents Chemother. 2014;58(5):2944-2947. doi:10.1128/AAC.02693-13

36. Franzblau SG, DeGroote MA, Cho SH, et al. Comprehensive analysis of methods used for the evaluation of compounds against Mycobacterium tuberculosis. Tuberculosis (Edinb). 2012;92 (6):453-488. doi:10.1016/j.tube.2012.07.003

37. Upton AM, Cho S, Yang TJ, et al. In vitro and in vivo activities of the nitroimidazole TBA-354 against Mycobacterium tuberculosis. Antimicrob Agents Chemother. 2015;59(1):136-144. doi:10.1128/AAC.03823-14

38. Zhang F, Li S, Wen S, et al. Comparison of in vitro susceptibility of mycobacteria against PA-824 to identify key residues of Ddn, the deazoflavin-dependent nitroreductase from Mycobacterium tuberculosis. Infect Drug Resist. 2020;13:815-822. doi:10.2147/IDR.S240716 
39. Zhuang Z, Wan D, Ding J, et al. Synergistic activity of nitroimidazole-oxazolidinone conjugates against anaerobic bacteria. Molecules. 2020;25(10):10. doi:10.3390/molecules25102431

40. Matsumoto M, Hashizume H, Tomishige T, et al. OPC-67683, a nitro-dihydro-imidazooxazole derivative with promising action against tuberculosis in vitro and in mice. PLoS Med. 2006;3(11): e466. doi:10.1371/journal.pmed.0030466

41. Stott KE, Pertinez H, Sturkenboom MGG, et al. Pharmacokinetics of rifampicin in adult TB patients and healthy volunteers: a systematic review and meta-analysis. $J$ Antimicrob Chemother. 2018;73 (9):2305-2313. doi:10.1093/jac/dky152

42. Daskapan A, Idrus LR, Postma MJ, et al. A systematic review on the effect of HIV infection on the pharmacokinetics of first-line tuberculosis drugs. Clin Pharmacokinet. 2019;58(6):747-766. doi:10.1007/ s40262-018-0716-8

43. Abdel-Rahman SM. CPMT project no. 16-020: review of evidence on the use of delamanid supplementing MDR-TB treatment regimens in children aged 6 years and above. Technical Study report prepared for the World Health Organization. Final Report. Geneva, Switzerland. July 1, 2016.

44. Lenaerts AJ, Gruppo V, Marietta KS, et al. Preclinical testing of the nitroimidazopyran PA-824 for activity against Mycobacterium tuberculosis in a series of in vitro and in vivo models. Antimicrob Agents Chemother. 2005;49(6):2294-2301. doi:10.1128/AAC.49.6.2294-2301.2005

45. Dutta NK, Karakousis PC. PA-824 is as effective as isoniazid against latent tuberculosis infection in $\mathrm{C} 3 \mathrm{HeB} / \mathrm{FeJ}$ mice. Int $J$ Antimicrob Agents. 2014;44(6):564-566. doi:10.1016/j.ijantimicag.2014.07.012

46. Lanoix JP, Betoudji F, Nuermberger E. Novel regimens identified in mice for treatment of latent tuberculosis infection in contacts of patients with multidrug-resistant tuberculosis. Antimicrob Agents Chemother. 2014;58(4):2316-2321. doi:10.1128/AAC.02658-13

47. Tasneen R, Williams K, Amoabeng O, et al. Contribution of the nitroimidazoles PA-824 and TBA-354 to the activity of novel regimens in murine models of tuberculosis. Antimicrob Agents Chemother. 2015;59(1):129-135. doi:10.1128/AAC.03822-14

48. Dutta NK, Alsultan A, Gniadek TJ, et al. Potent rifamycin-sparing regimen cures guinea pig tuberculosis as rapidly as the standard regimen. Antimicrob Agents Chemother. 2013;57(8):3910-3916. doi:10.1128/AAC.00761-13

49. Ahmad Z, Peloquin CA, Singh RP, et al. PA-824 exhibits time-dependent activity in a murine model of tuberculosis. Antimicrob Agents Chemother. 2011;55(1):239-245. doi:10.1128/ AAC.00849-10

50. Drusano GL, Neely MN, Kim S, et al. Building optimal three-drug combination chemotherapy regimens. Antimicrob Agents Chemother. 2020;64(11):11. doi:10.1128/AAC.01610-20

51. Drusano GL, Kim S, Almoslem M, et al. The funnel: a screening technique for identifying optimal two-drug combination chemotherapy regimens. Antimicrob Agents Chemother. 2021;65:2.

52. Muliaditan M, Della Pasqua O. Evaluation of pharmacokinetic-pharmacodynamic relationships and selection of drug combinations for tuberculosis. Br J Clin Pharmacol. 2021;87 (1):140-151. doi:10.1111/bcp.14371

53. Dawson R, Diacon AH, Everitt D, et al. Efficiency and safety of the combination of moxifloxacin, pretomanid (PA-824), and pyrazinamide during the first 8 weeks of antituberculosis treatment: a phase 2b, open-label, partly randomised trial in patients with drug-susceptible or drug-resistant pulmonary tuberculosis. Lancet. 2015;385(9979):1738-1747. doi:10.1016/S0140-6736(14)62002-X

54. Diacon AH, Dawson R, Du Bois J, et al. Phase II dose-ranging trial of the early bactericidal activity of PA-824. Antimicrob Agents Chemother. 2012;56(6):3027-3031. doi:10.1128/AAC.06125-11

55. Diacon AH, Dawson R, von Groote-bidlingmaier F, et al. Bactericidal activity of pyrazinamide and clofazimine alone and in combinations with pretomanid and bedaquiline. Am J Respir Crit Care Med. 2015;191(8):943-953. doi:10.1164/rccm.201410-1801OC
56. Diacon AH, Dawson R, von Groote-bidlingmaier F, et al. 14-day bactericidal activity of PA-824, bedaquiline, pyrazinamide, and moxifloxacin combinations: a randomised trial. Lancet. 2012;380 (9846):986-993. doi:10.1016/S0140-6736(12)61080-0

57. Nedelman JR, Salinger DH, Subramoney V, et al. An exposure-response perspective on the clinical dose of pretomanid. Antimicrob Agents Chemother. 2020;65(1):1. doi:10.1128/ AAC.01121-20

58. Lyons MA. Pretomanid dose selection for pulmonary tuberculosis: an application of multi-objective optimization to dosage regimen design. CPT. 2021;10(3):211-219.

59. Center for Drug Evaluaton and Research. Product quality review for application number 212862Orig1s000. October 15, 2017.

60. Lyons MA. Modeling and simulation of pretomanid pharmacokinetics in pulmonary tuberculosis patients. Antimicrob Agents Chemother. 2018;62(7). doi:10.1128/AAC.02359-17

61. Ginsberg AM, Laurenzi MW, Rouse DJ, Whitney KD, Spigelman MK. Safety, tolerability, and pharmacokinetics of PA-824 in healthy subjects. Antimicrob Agents Chemother. 2009;53 (9):3720-3725. doi:10.1128/AAC.00106-09

62. Winter H, Ginsberg A, Egizi E, et al. Effect of a high-calorie, high-fat meal on the bioavailability and pharmacokinetics of PA-824 in healthy adult subjects. Antimicrob Agents Chemother. 2013;57 (11):5516-5520. doi:10.1128/AAC.00798-13

63. Ignatius EH, Abdelwahab MT, Hendricks B, et al. Pretomanid pharmacokinetics in the presence of rifamycins: interim results from a randomized trial among patients with tuberculosis. Antimicrob Agents Chemother. 2021;65(2):2. doi:10.1128/AAC.01196-20

64. Pretomanid [labeling]. New York: Mylan; 2019.

65. Shobo A, Bratkowska D, Baijnath S, et al. Tissue distribution of pretomanid in rat brain via mass spectrometry imaging. Xenobiotica. 2016;46(3):247-252. doi:10.3109/00498254.2015. 1067935

66. Center for Drug Evaluaton and Research. Multidisciplinary review for application number 212862Orig1s000. August 13, 2019.

67. Dooley KE, Luetkemeyer AF, Park JG, et al. Phase I safety, pharmacokinetics, and pharmacogenetics study of the antituberculosis drug PA-824 with concomitant lopinavir-ritonavir, efavirenz, or rifampin. Antimicrob Agents Chemother. 2014;58(9):5245-5252. doi:10.1128/ AAC.03332-14

68. Winter H, Egizi E, Erondu N, et al. Evaluation of pharmacokinetic interaction between PA-824 and midazolam in healthy adult subjects. Antimicrob Agents Chemother. 2013;57(8):3699-3703. doi:10.1128/ AAC.02632-12

69. Wang L, Xu Y, Liang L, et al. LC-MS/MS method for the simultaneous determination of PA-824, moxifloxacin and pyrazinamide in rat plasma and its application to pharmacokinetic study. J Pharm Biomed Anal. 2014;97:1-8. doi:10.1016/j.jpba.2014.03.046

70. Wang L, Zhao J, Zhang R, et al. Drug-Drug interactions between PA-824 and darunavir based on pharmacokinetics in rats by LC-MSMS. J Chromatogr Sci. 2018;56(4):327-335. doi:10.1093/chromsci/ bmy002

71. Ginsberg AM, Laurenzi MW, Rouse DJ, Whitney KD, Spigelman MK. Assessment of the effects of the nitroimidazo-oxazine PA-824 on renal function in healthy subjects. Antimicrob Agents Chemother. 2009;53(9):3726-3733. doi:10.1128/ AAC.00112-09

72. Li H, Salinger DH, Everitt D, et al. Long-term effects on QT prolongation of pretomanid alone and in combinations in patients with tuberculosis. Antimicrob Agents Chemother. 2019;63(10). doi:10.1128/AAC.00445-19

73. Pretomanid. Drugs and Lactation Database (Lactmed). Bethesda (MD): National Library of Medicine (US); 2020.

74. Miele K, Bamrah Morris S, Tepper NK. Tuberculosis in pregnancy. Obstet Gynecol. 2020;135(6):1444-1453. doi:10.1097/ AOG.0000000000003890 
75. Conradie F, Diacon AH, Ngubane N, et al. Treatment of highly drug-resistant pulmonary tuberculosis. $N$ Engl J Med. 2020;382 (10):893-902. doi:10.1056/NEJMoa1901814

76. Howell P. Final results of the NIX-TB clinical study of BPaL regimen for highly resistant tuberculosis. Presented at: Conference on Retroviruses and Opprotunistic Infections; March 6-10, 2021; Virtual Platform.

77. Haley CA, Macias P, Jasuja S, et al. Novel 6-month treatment for drug-resistant tuberculosis, United States. Emerg Infect Dis. 2021;27 (1):332-334. doi:10.3201/eid2701.203766

78. Tweed CD, Wills GH, Crook AM, et al. A partially randomised trial of pretomanid, moxifloxacin and pyrazinamide for pulmonary TB. Int $J$ Tuberc Lung Dis. 2021;25(4):305-314. doi:10.5588/ ijtld.20.0513

79. Tweed CD, Dawson R, Burger DA, et al. Bedaquiline, moxifloxacin, pretomanid, and pyrazinamide during the first 8 weeks of treatment of patients with drug-susceptible or drug-resistant pulmonary tuberculosis: a multicentre, open-label, partially randomised, phase $2 \mathrm{~b}$ trial. Lancet Respir Med. 2019;7(12):1048-1058. doi:10.1016/ S2213-2600(19)30366-2

80. TB Alliance. Pretomanid sponsor briefing document for the antimicrobial drugs advisory committee. Available from: https://www.fda. gov/media/127593/download. Accessed March 5, 2021.
81. World Health Organization. Guidelines approved by the guidelines review committee. In: WHO Consolidated Guidelines on Tuberculosis: Module 4: Treatment - Drug-Resistant Tuberculosis Treatment. Geneva: World Health Organization (c) World Health Organization 2020; 2020.

82. Mirzayev F, Viney K, Linh NN, et al. World Health Organization recommendations on the treatment of drug-resistant tuberculosis, 2020 update. Eur Respir J. 2020. doi:10.1183/13993003.03300-2020

83. Sweeney S, Gomez G, Kitson N, et al. Cost-effectiveness of new MDR-TB regimens: study protocol for the TB-PRACTECAL economic evaluation substudy. BMJ Open. 2020;10(10):e036599. doi:10.1136/bmjopen-2019-036599

\section{Publish your work in this journal}

Drug Design, Development and Therapy is an international, peerreviewed open-access journal that spans the spectrum of drug design and development through to clinical applications. Clinical outcomes, patient safety, and programs for the development and effective, safe, and sustained use of medicines are a feature of the journal, which has also been accepted for indexing on PubMed Central. The manuscript management system is completely online and includes a very quick and fair peer-review system, which is all easy to use. Visit http://www. dovepress.com/testimonials.php to read real quotes from published authors. 